\title{
As limitações das políticas de habitação portuguesas: reflexões sobre a importância da intersetorialidade
}

\section{The limitations of Portuguese housing policy: reflexions on the importance of intersectorial action}

Raquel de Oliveira Barreto ${ }^{1}$

Ana Paula Paes de Paula ${ }^{2}$

Felipe Marques Carabetti Gontijo ${ }^{3}$

\begin{abstract}
Resumo
Partindo de uma perspectiva neoliberal e sob um discurso moderno de descentralização estatal e participação da sociedade civil, o Estado português tem utilizado parcerias com o setor cooperativo nas suas políticas habitacionais. Frente à visibilidade alcançada por estas políticas recentes na Comunidade Européia, bem como a aproximação que vem ocorrendo entre Portugal e Brasil para troca de experiências neste campo, este trabalho tem como objetivo analisar como estas políticas portuguesas têm se desenvolvido e quais suas implicações para a população brasileira. Para isso, investigaram-se dois projetos de realocação de pessoas carentes em bairros sociais. A metodologia utilizada foi de caráter qualitativo, baseada em pesquisa documental, além de entrevistas e observações in loco. Os resultados apontam para políticas habitacionais bastante desarticuladas e, em consequência disso, pouco efetivas. Os casos estudados corroboram o argumento de que, apesar do discurso, o governo assumiu na realidade uma posição de transferência das responsabilidades para a sociedade civil por meio das cooperativas de habitação, e que a criação de bairros sociais acaba por contribuir para o aumento da estigmatização e do preconceito. Além disso, enfatizam a importância de uma ação intersetorial nas políticas habitacionais.
\end{abstract}

Palavras-chave: Políticas Sociais, Cooperativismo de Habitação, Portugal, Intersetorialidade

\begin{abstract}
From the neoliberal perspective and using discourse concerning the decentralization of the modern state and the participation of civil society, the Portuguese State has used partnerships with the cooperative sector in our housing policies. In light of the visibility achieved by these recent policies vis-à-vis the European Community, the approach is also taking place between Portugal and Brazil to exchange experiences in this field. This work aims to analyze how these Portuguese policies have developed and their implications for the Brazilian population. For this purpose, we investigated two projects of relocation socially needy people in certain neighborhoods. The methodology used was of a qualitative nature, based on documental research, interviews and observations. The results suggest quite disjointed and, as a result, not very effective housing policies. The cases studied corroborate the argument that, despite the discourse, the government actually transferred responsibility to civilian society through housing cooperatives. They also show that the creation of social neighborhoods actually end up increasing stigma and prejudice. Furthermore, they emphasize the importance of intersectoral action in housing policies.
\end{abstract}

Keywords: Social Policies, Cooperativism Housing, Portugal, Intersectoral Action

\footnotetext{
Artigo submetido em maio e aceito para publicação em outubro de 2010.

${ }^{1}$ Mestranda do Centro de Pós-Graduação e Pesquisa em Administração da Universidade Federal de Minas Gerais; Bacharel em Administração (FACEUFMG). Endereço: Av. Antônio Carlos, 6627 - sala 4062 - FACE-UFMG, Pampulha, Belo Horizonte/MG CEP 31270-901; Email: admraquelf@hotmail.com ${ }^{2}$ Doutora em Ciências Sociais (IFCH-UNICAMP); Profa. Adjunta do do Centro de Pós-Graduação e Pesquisa em Administração da Universidade Federal de Minas Gerais. Endereço: Av. Antônio Carlos, 6627 - sala 4033 - FACE-UFMG. Pampulha. Belo Horizonte/MG CEP 31270-901; Email: appaula@face.ufmg.br

${ }^{3}$ Mestrando do Centro de Pós-Graduação e Pesquisa em Administração da Universidade Federal de Minas Gerais; Bacharel em Ciências Sociais (FAFICH-UFMG) Endereço: Av. Antônio Carlos, 6627 - sala 4062 - FACE-UFMG, Pampulha, Belo Horizonte/MG CEP 31270-901. Email: felcarabetti@yahoo.com.br
} 


\section{Introdução}

Atualmente, a falta de acesso à terra ainda é uma fator gerador de desigualdades sociais. Mesmo que a Revolução Industrial tenha alterado os paradigmas de riqueza - da posse da terra para a de máquinas e, atualmente para o conhecimento e o domínio da tecnologia -, a preocupação com a propriedade fundiária persiste de forma intensa, principalmente, por parte dos que dela se veem apartados (BASSUL, 2002). Se antes isso era evidente em relação à propriedade rural, ao latifúndio, na contemporaneidade essas diferenças se destacam no contexto urbano, fazendo com que aqueles que não possuem poder de compra tenham que se alojar em locais distantes dos centros urbanos, ficando muitas vezes excluídos do acesso aos serviços públicos ou sendo mal atendidos.

Essa questão da precariedade habitacional é um assunto comum a diversos países. No caso de Portugal, objeto de estudo deste trabalho, tal situação pode ser considerada um reflexo do fato de que a política habitacional foi colocada em segundo plano durante muito tempo. Nas últimas décadas houve um agravamento da situação, em decorrência, principalmente, do êxodo rural, das dinâmicas migratórias pós-descolonização e da falta de infraestrutura para lidar com a integração de um novo contingente populacional que passou a habitar as áreas metropolitanas nas décadas de 1960 e de 1970 . O Estado Novo (ditadura salazarista) mostrava ineficiência para lidar com esses problemas, em parte, pelas características inerentes ao regime ditatorial, como ausência de liberdades civis, maior centralização do Estado, inércia, empecilhos a reformas políticas e gastos excessivos com as guerras e a administração coloniais (SILVA, 2001). Como resultado, um grande número de "barracas"4 e de moradias precárias, cujos moradores eram majoritariamente de origem cigana e africana, espalhou-se por metrópoles como Lisboa.

Nos anos 1960, o país confrontou-se com a necessidade de criar as suas próprias políticas públicas de bemestar, ainda que alguns dos integrantes do governo português questionassem os princípios do Welfare State (IHRU, 2007). Assim, nos anos 1970, enquanto os demais países europeus colocavam em pauta a discussão acerca da viabilidade ou não do Estado de Bem-Estar Social tal como fora concebido no pós-guerra, tendendo a propor o seu enxugamento, Portugal encontrava-se numa posição desconfortável, pois, até então, o país não tinha desenvolvido de forma sistemática políticas sociais universalistas e tendia a alinhar-se com o discurso majoritário neoliberal então vigente, o qual criticava um suposto "paternalismo" do Estado e defendia políticas sociais focalizadas.

Um episódio importante na história portuguesa foi a Revolução dos Cravos, que pôs fim ao período ditatorial do Estado Novo, dando origem ao "Programa dos três D: Democratizar, Descolonizar e Desenvolver". Em 25 de abril de 1975, ocorreram eleições livres para a Assembleia Constituinte, que elaborou uma nova Constituição, com fortes características socialistas, e instituiu o regime de democracia parlamentar, no qual a habitação digna foi apresentada como um direito da população (SILVA, 2001). Entretanto, apesar da questão habitacional ter sido contemplada na nova Constituição, ela, ainda assim, não se tornou uma questão central para o governo português, que se identificava como os princípios neoliberais que então começavam a vigoravam nos EUA e na Europa. Isso culminou numa realidade marcada pela insuficiência de moradias para a população carente, pela criação de bairros sociais sem planejamento adequado e pela existência de bairros sociais degradados.

A pouca importância atribuída pelo governo português à habitação se confirma no diagnóstico apresentado pela União Europeia sobre a questão habitacional nos seus países constituintes, o qual aponta o baixo investimento do país no setor:

Portugal, Espanha e a Grécia têm um sector particularmente vasto de alojamento ocupado pelos respectivos proprietários, ao passo que o número de alojamentos de aluguer de carácter social é mínimo e (até há pouco tempo) o sector de alojamento de aluguer de modesta qualidade de carácter 
privado está em declínio. A despesa pública com a política relativa à habitação é inferior a $1 \%$ do PIB (POLÍTICA DE HABITAÇÃO NOS ESTADOS MEMBROS DA UE, 1996, grifo nosso).

Percebe-se, portanto, que o valor da verba pública destinada à habitação é ínfimo, o que reafirma a percepção de que se trata de uma política tida como secundária. Pelo documento, é possível perceber que, apesar da União Europeia não ter competência para legislar sobre a matéria política habitacional, reconhece a sua importância. Neste documento há uma tentativa da UE de diagnosticar como tais políticas têm sido tratadas nos países membros e de apresentar recomendações sobre como se podem promover políticas sociais mais coesas. Além disso, são apontados os desafios para as políticas habitacionais, como a acessibilidade às moradias para os semabrigo e a melhoria de suas condições de vida.

No programa do atual governo português, em vigor desde 2007, há um reconhecimento de que o país ainda enfrenta problemas habitacionais e a proposição de um modelo alternativo de intervenção.

Portugal tem, ainda, carências ao nível habitacional. Continua a ser necessário promover habitação social, em articulação com outras políticas sociais e com um maior envolvimento de entidades, privadas e do setor cooperativo e social. As politicas integradas e transversais de integração social junto das populações realojadas visarão à prevenção da criação de novos "guetos" (XVII GOVERNO CONSTITUCIONAL, 2007, p.102).

A proposta de políticas integradas e transversais é coerente, inclusive, com as recomendações da União Europeia. No entanto, a questão principal reside na forma de operacionalização dessa proposta, ou seja, em como transmutá-la em ações concretas para a resolução dos problemas reais da população, pois a maneira como essas ações são delineadas definem a efetividade dessas políticas. No que se refere a essas ações, o caso português apresenta lições de como o tratamento inadequado das políticas habitacionais pode resultar no agravamento da situação de exclusão e aponta para importância da intersetorialidade no trato destas questões. Mas, enfim, porque estudar as políticas portuguesas?

Essa investigação torna-se relevante pela própria visibilidade que essas políticas habitacionais mais recentes têm alcançado na Comunidade Européia, inclusive sendo objeto de análise para premiação, como é o caso da experiência de São João da Talha, que abordamos neste artigo ${ }^{5}$. Além disso, a pesquisa realizada evidenciou que está ocorrendo uma aproximação entre Portugal e Brasil para troca de experiências nesta área principalmente no que diz respeito ao modelo cooperativista. Assim, atualmente, as políticas de habitação portuguesas têm sido pautadas por um discurso moderno e democrático que defende a descentralização do aparelho estatal associada à participação da sociedade civil, de modo que é fundamental entender mais aprofundadamente como tais políticas têm sido desenvolvidas, suas implicações para a sociedade, além de questionar quais seriam seus efeitos se trazidas para realidade brasileira.

Dessa forma, é no sentido de analisar a problemática das políticas de habitação portuguesas mais recentes - as quais se pautam pela interface entre os domínios público e privado - que se delineou o objetivo deste estudo, tendo em vista refletir sobre quais são as suas reais contribuições para a construção de ações mais efetivas para a redução da exclusão social no campo das políticas habitacionais. Para isso, foram investigadas duas experiências: os casos dos bairros Sá Carneiro e São João da Talha, os quais consistem em projetos de realocação de pessoas carentes em bairros sociais. Para atingir tais objetivos, este estudo está organizado em quatro seções, além desta introdução. Na primeira seção é apresentada a fundamentação teórica da pesquisa, a qual perpassa a questão da intersetorialidade e a política de habitação em Portugal. Logo após são explicitadas as opções metodológicas, apresentados os casos analisados e realizada uma reflexão sobre eles, seguindo-se as considerações finais.

\footnotetext{
${ }^{5}$ Quando estávamos realizando a coleta de dados em São João da Talha, presenciamos a avaliação feita por uma comissão da Comunidade Européia tendo em vista uma premiação para iniciativas que se destacassem no campo social.
} 


\section{Fundamentação teórica}

\section{Políticas de habitação social: uma visão intersetorial}

O direito à habitação digna está presente na maior parte das constituições de países democráticos. Mais do que oferecer moradia àqueles que não têm condições de adquiri-la, isso implica questões como a inserção social e o exercício de cidadania. No entanto, o Estado tem se mostrado ineficiente: o excesso de burocratização, ou a falta de vontade política, vem distanciando cada vez mais o governo das demandas sociais, culminando inevitavelmente num gap entre o que se precisa fazer e o que de fato é feito. Além disso, outro gap pode ser percebido entre o discurso das políticas e a realidade de sua implementação. Como explicitado por Augusto (2002), essas políticas se desvirtuam na medida em que fazem com que as pessoas se tornem meros recebedores de moradias, quando deveriam promover a participação delas como protagonistas de uma realidade que lhes é própria.

Como explicitado por Augusto (2002), citando Almeida (1994), a habitação social surgiu seguindo esse mesmo percurso, pautada por ações realizadas de um modo excessivamente funcionalista, que deixam a desejar no que tange à adequação entre o que é feito e as reais necessidades e especificidades do local e da comunidade atingida. A construção dos bairros sociais tem despertado sentimentos de segregação e de exclusão, resultados antagônicos em relação aos objetivos propostos de inclusão e integração social. Como explicitado por Guerra (1994), a principal consequência dessas políticas tem sido a formação de guetos, nos quais a população se vê afastada dos centros decisórios e sem acesso aos serviços públicos essenciais, o que contribui para uma situação de exclusão cada vez mais ampliada.

Na verdade, o primeiro passo para se pensar políticas sociais mais efetivas, entre as quais se incluem também as políticas de habitação, é a superação do entendimento tradicional do que seja pobreza e exclusão, baseado numa perspectiva unidimensional monetária, pois esta se mostra insuficiente para a abordagem de tal questão. Como explicitado anteriormente, essa visão unidimensional remete, no caso habitacional, à resolução dos problemas por meio do simples fornecimento de moradia. Em uma perspectiva mais ampla, a da intersetorialidade nas políticas sociais, busca-se outra forma de compreensão e de enfrentamento do problema pelos atores sociais (Estado, sociedade civil, terceiro setor e setor privado).

As condições de privação são entendidas nessa perspectiva como um fenômeno de caráter multideterminado e multidimensional. Como coloca Bronzo (2007, p.8) "nas situações de pobreza convergem fatores de natureza socioeconômica, culturais, familiares, individuais e institucionais, conformando trajetórias distintas". Essa percepção da pobreza permite um entendimento multifacetado "de carências e privações em interação, sustentando-se reciprocamente, gerando círculos perversos de exclusão". Citando Corera (2007), a autora identifica seis dimensões relevantes na análise dos processos de exclusão social: (a) a dimensão econômica, expressa pela ausência da renda; (b) o acesso a bens e serviços, que marcam a situação de inserção e de não inserção de famílias e indivíduos no conjunto das políticas de proteção; (c) o mundo do trabalho, que diz respeito não só a renda, mas também a uma identidade e dignidade social; (d) os laços sociais e a vigência de mecanismos de solidariedade e reciprocidade; (e) os aspectos subjetivos, relativos a valores e atitudes; e, finalmente, (f) a dimensão da territorialidade, que se refere ao estigma e à segregação (BRONZO, 2007).

Segundo Bronzo (2007), para superar de forma sustentável as situações de exclusão é imperativo desenvolver um conjunto de ações, intersetorialmente articuladas, que são mais do que uma simples conexão ou agregação de setores. A autora explicita ainda que, por ser um fenômeno coletivo, a pobreza e a exclusão devem ser coletivamente enfrentadas pelo conjunto das políticas e dos diversos atores e setores sociais, não só pelo Estado. A intersetorialidade é aqui entendida em sua dupla dimensão: "ao mesmo tempo conceitual/substantiva (no plano da concepção do problema e apreensão da realidade, no âmbito cognitivo) e institucional/organizacional (no campo da organização e gestão, no âmbito operacional)" (Ibidem, p.13).

O âmbito operacional da intersetorialidade implica a necessidade de setores da administração pública responsáveis, de alguma forma, por políticas sociais e econômicas, atuarem de forma conjunta no diagnóstico, no planejamento, na execução e na correção das políticas públicas. Assim, seria abarcada toda a complexidade 
do fenômeno em questão, com maior eficácia das atividades desenvolvidas pela melhoria das condições de vida do cidadão.

Algumas das estratégias para aumentar o efeito dessas políticas são a descentralização nos processos decisórios - bem como nas etapas de diagnóstico, planejamento, execução e correção - e o aumento da participação da população beneficiada nessas etapas e nas esferas de decisão em nível local. Acredita-se que a proximidade entre a administração local e a população em questão traria contribuições para uma atuação mais precisa na solução dos problemas. A gestão por meio de órgãos transversais, entendidos como "sistemas de relacionamento e de conhecimento e que alimentam as organizações de visões específicas e objetivos estratégicos de mudança social" (SERRA apud BRONZO, 2007, p.14) também é outra estratégia para o combate eficaz dos problemas sociais.

Segundo Bronzo (2007), a transversalidade é importante, pois permite conferir uma visibilidade horizontal à organização, sem que sejam desconsideradas a qualidade técnica e a especialização, dimensões fundamentais que dão forma à estrutura da organização. É forçoso, ao menos, registrar que, apesar dessas possibilidades colocadas pela intersetorialidade, essa proposta de gestão enfrenta grandes desafios em sua operacionalização, tais como: inexistência de sistemas de informações integrados; destinação de recursos de forma setorializada; diferenças de objetivos, de dinâmicas e de culturas organizacionais entre as instituições e setores; além da disputa por recursos e por poder entre setores da administração pública, entre outros.

Apesar de reconhecermos essas limitações, é a partir da concepção de intersetorialidade, tanto em seu âmbito cognitivo quanto em seu âmbito operacional, que se pretende analisar as tentativas portuguesas de resolução do problema da carência habitacional, assim como seus resultados. Entendemos que somente por essa via é possível superar de fato o problema da moradia e da exclusão social.

\section{A política de habitação em Portugal: um breve panorama histórico e o papel das cooperativas}

De acordo com Silva (2001), as políticas habitacionais em Portugal até o fim do Estado Novo possuíam um caráter ruralista, o que de certa forma contribuiu para um atraso em termos de industrialização e urbanização do país. Tais políticas tinham como fundamento o livre mercado. Isto é, a pouca intervenção estatal direta na construção de habitações, se comparada com os padrões europeus da época, direcionava-se quase exclusivamente para empreendimentos que geravam rentabilidade. Além disso, a atuação corporativa do Estado, ao fornecer habitações em bairros sociais por meio de habitações econômicas, eram apelativas dos pontos de vista simbólico e político. Do início do Estado Novo até os anos 1960, a atuação estatal para sanar o problema habitacional se resumiu à oferta de habitações econômicas em bairros sociais e ao congelamento dos aluguéis, ${ }^{6}$ como tentativa de amenizar o quadro de especulação imobiliária, deixando a cargo dos setores privado e corporativo grande parte do fornecimento de habitação, tanto para compra quanto para aluguel.

A partir de 1965, houve pequenas mudanças de contexto, uma vez que a eclosão das guerras coloniais e a inserção na Associação Europeia de Livre Comércio propiciaram uma maior abertura ao mercado externo e também um maior desenvolvimento tecnológico do setor agrícola. Os resultados dessas mudanças foram uma intensificação do êxodo rural e um surto imigratório que culminou numa ocupação desordenada do espaço urbano no país. Dessa forma, a incapacidade de atender à demanda crescente por moradia fez com que a intervenção estatal fosse ainda mais necessária. Tal intervenção se deu nos seguintes âmbitos: criação de um Fundo de Fomento à Habitação em 1969; criação da Secretaria de Estado da Habitação e Obras Públicas; alterações na lei dos Solos e repressão à construção de moradias clandestinas, além do incentivo ao setor cooperativo, processo esse que só foi colocado em prática em 1974.

Segundo Silva (2001), é a partir de 1974, com o já apontado fim do período ditatorial, que mudanças legais mais significativas foram empreendidas. Com o término do Estado Novo, o país tentou avançar de forma a

\footnotetext{
${ }^{6}$ Regime de controle de arrendamento (congelamento de aluguéis) estabelecido na legislação dos anos 1940, mas que continua valendo para os contratos firmados até 1985. Para se ter uma ideia, em 2001, ainda representava por volta de $60 \%$ dos arrendamentos (IHRU, 2008). Esses arrendamentos em regime "especial" causam diversas distorções no mercado de aluguéis, bem como resultados perniciosos para ambos os envolvidos, locatários e locadores.
} 
superar o atraso econômico, por meio de um Estado mais participativo, inclusive, na promoção da habitação, com medidas específicas referentes à urbanização e à utilização dos solos. Contudo, a questão habitacional agravou-se devido à retração da procura habitacional e do mercado de terrenos. É importante lembrar que a Revolução dos Cravos ocorre num contexto de recessão da economia mundial iniciada em 1973 e de consequente restrição aos créditos bancários. Entre os diversos objetivos dessa nova fase do país, destaca-se a promoção de habitações cooperativas. O Fundo de Fomento à Habitação criou um setor específico para o apoio às cooperativas, sendo, inclusive, o cooperativismo e o associativismo considerados objetivos presentes na nova Constituição do país, no que tange aos ideais sociais estabelecidos.

No entanto, nessa época, a participação do cooperativismo na habitação era ainda bastante incipiente, representando menos de $1 \%$ da produção licenciada de habitações. Desde 1976, o cooperativismo recebe tratamento especial no que diz respeito à legislação, pois a Constituição portuguesa daquele ano já delimitava o setor cooperativo como independente do público e do privado. Em 1980, foi publicado o Código Cooperativo, com a finalidade de estabelecer a regulamentação para o setor. Após a criação desses primeiros instrumentos legislativos, observou-se uma rápida expansão do setor. Já ao final da década de 1970, cerca de 250 cooperativas dessa modalidade tinham sido criadas. Nesse cenário, houve então a necessidade de criação de uma estrutura organizativa e, para isso, foi criada Federação Nacional de Cooperativas de Habitação Econômica (Fenache).

A partir da nova Constituição portuguesa, houve inovações quanto às políticas públicas e ao modelo de gestão. Destaca-se um aumento do poder local, que se refletiu em uma maior preocupação com os espaços públicos, com a degradação das habitações e com as condições de saneamento. Entre as propostas estava a resolução de questões como o abastecimento de água e de luz, o tratamento de esgoto, bem como a remoção das "barracas" e o realojamento das famílias que nelas habitavam. Esse último objetivo foi intensificado a partir dos anos 1990 com o Programa Especial de Realojamento (PER), o qual tem o intuito de erradicar tal tipo de habitação das áreas metropolitanas de Lisboa e do Porto. Além do realojamento, o projeto prevê uma revitalização dos imóveis municipais e também a realização de ações sociais para acompanhar o processo de integração social das famílias, assegurando-lhes condições para que no futuro possam ter suas próprias moradias.

Silva (2001) assinala ainda que no período de 1986 a 1993, Portugal passou por intensas transformações econômicas advindas da sua inserção na então Comunidade Econômica Europeia. Houve um expressivo crescimento econômico que, por outro lado, culminou na intensificação da imigração para as principais cidades do país, como Lisboa. Nesse sentido, as políticas habitacionais também se modificaram, de forma a se adequarem aos moldes internacionais de participação da população e de descentralização. Dessa forma, o caminho contrário foi traçado: o Estado novamente diminuiu sua intervenção, mas se manteve como controlador. O setor cooperativo aparece, portanto, como um ator importante no atendimento das necessidades de moradias, não apenas no que se refere à construção, mas também ao reparo e à conservação de imóveis degradados.

A partir de 1993, a economia portuguesa, que passara por um período de recessão, voltou a se expandir e, consequentemente, a população passou a consumir e a investir mais. Com o acesso ao crédito para habitação facilitado, o mercado tornou-se mais competitivo. Todas essas questões alteraram significativamente o mercado de habitação e o parque habitacional português. De acordo com o relatório do Instituto de Habitação e Reabilitação Urbana (IHRU), as dinâmicas observadas no nível da procura - "aumento do rendimento das famílias, descida das taxas de juros na UE, melhoria substancial das condições de crédito para a aquisição de habitação potenciada pelos apoios e incentivos fiscais do Estado, inércia do mercado de arrendamento" - e da oferta - "crescimento do número de empresas de construção e de imobiliárias, concentração e entrada de

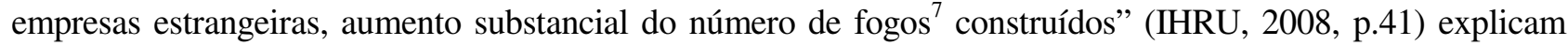
essas alterações. A inércia e a baixa atratividade do mercado de arrendamento decorrem, entre outras coisas, das facilidades propiciadas pelo crédito para a aquisição de habitação, que permite um encargo mensal próximo do que seria o aluguel ao preço de mercado (redução da procura). Decorrem também da legislação e do sistema

\footnotetext{
${ }^{7}$ Palavra utilizada no português de Portugal para designar habitação ou unidade habitacional.
} 
judicial que não tornam o aluguel uma fonte de rendimento atrativa, por acarretar riscos ao proprietário (diminuição da oferta).

É interessante informar que, atualmente, Portugal, apesar de ter milhares de famílias sem moradia decente, apresenta um superávit habitacional em números absolutos, ou seja, há muitos imóveis desocupados. Os motivos desse fenômeno são o aumento do número de residências secundárias, devido aos movimentos migratórios dos distritos do interior para os do Porto e de Lisboa - deixando casas ociosas nas regiões de onde emigram - e o maior número de aquisições de habitações sazonais, principalmente, nas áreas litorâneas.

O foco das políticas de habitação voltou-se então para o desenvolvimento de projetos de cunho social, como por exemplo, os criados para a remoção de famílias ciganas de moradias ilegais, caso que será abordado neste estudo. Tal enfoque abriu mais espaço para a atuação das instituições privadas de solidariedade social e do setor cooperativo (SILVA, 2001).

Em 1995, a Fenache respondeu pela construção de 160.000 habitações, o que significa que 6\% da população nacional da época foi beneficiada por esse tipo de habitação. Em entrevista concedida a nós em 2008, Manuel Terezo, presidente da Fenache, afirmou que há dados que revelam que o país chegou a ter 500 cooperativas de habitação. No entanto, esse número foi sendo reduzido tanto pela falência de alguns empreendimentos, quanto pelo fato de alguns deles terem se desfeito em decorrência do alcance de objetivos específicos para os quais foram criados, resultando atualmente num quadro de 70 cooperativas ativas no país. Além da construção em si, existem organizações que se dedicam à prestação de serviços, como administração de condomínios, obras sociais e atividades culturais e esportivas, entre outros.

\section{A política de habitação atual}

Em Portugal, as condições do mercado imobiliário são bastante diferentes das do Brasil, pois naquele país praticamente inexistem imóveis para aluguel: a maior parte das casas ou apartamentos é comprada por meio de financiamento bancário ou de cooperativas habitacionais. Para a população carente são destinadas as habitações sociais, conhecidas no Brasil como casas ou apartamentos populares, que costumam ser arrendadas com o subsídio estatal, uma vez que há uma política progressiva para evitar que os imóveis sejam de propriedade das pessoas, pois se considera que a utilização de uma habitação social deve ser uma condição transitória, modificada pela ascensão social do indivíduo por meio do emprego. A política de habitação portuguesa é de responsabilidade do Ministério do Ambiente, do Ordenamento do Território e do Desenvolvimento Regional. No entanto, é o IHRU o órgão responsável pela implementação dessa política (IHRU, 2009).

Segundo o Programa do XVII Governo Constitucional, a política de habitação no país visa:

à promoção do acesso à habitação, à articulação das políticas de habitação com a qualificação do ambiente urbano e à concertação da intervenção do Estado com outras entidades privadas do setor cooperativo e associativo. Esta política tem três eixos de intervenção: dinamização do mercado de arrendamento, novas políticas sociais e requalificação do tecido urbano. (XVII GOVERNO CONSTITUCIONAL, 2007, p.100)

O primeiro eixo, a dinamização do mercado de arrendamento, diz respeito à tentativa do governo de dinamizar esse mercado nas cidades portuguesas "por via do aumento da oferta de imóveis para arrendamento, da mobilidade e da promoção do acesso de famílias e agentes econômicos a esse mercado" (XVII GOVERNO CONSTITUCIONAL, 2007, p.101). O governo - ou mais precisamente o IHRU - possui propriedades nas cidades portuguesas, que coloca à disposição da população para serem alugadas. Essa política tem algumas restrições a respeito de quem pode acioná-la. Para fazê-lo, o indivíduo tem que estar com a situação regularizada no país (no caso de imigrante), não pode ser proprietário de outra casa e deve apresentar os seguintes documentos: bilhete de identidade (BI); atestado de residência; número de identificação fiscal (NIF); última nota de liquidação de IRS, assim como os dois últimos recibos de vencimento (IHRU, 2009).

Além de disponibilizar imóveis para locação, o governo também agiria como agente intermediário entre donos de imóveis e possíveis locatários. Nesse eixo, temos então o chamado arrendamento social, que consiste no 
aluguel a preços muito baixos de apartamentos localizados nos "parques habitacionais", semelhantes a alguns conjuntos habitacionais brasileiros, que geralmente são de propriedade das câmaras municipais, ou de empresas de solidariedade social como as cooperativas habitacionais (que serão analisadas nesse estudo). Esses "parques" são conjuntos habitacionais onde pessoas de baixa renda e indivíduos realocados de "barracas" localizadas em diversos pontos da cidade têm possibilidade de ter uma casa.

Esses apartamentos são chamados em Portugal de habitação social. As propostas concretas do governo para esse eixo são, além de revisões legais, medidas complementares como: utilização de parcerias público-privadas na reabilitação de imóveis para arrendamento; programas de apoio financeiro e logístico à realização de obras de recuperação de edifícios; e a criação de centros de arbitragem para a resolução de conflitos relativos a contratos de arrendamento, no sentido de salvaguardar as relações contratuais (XVII GOVERNO CONSTITUCIONAL, 2007).

No segundo eixo, que abrange novas políticas sociais, o governo se propõe a continuar promovendo a habitação social em articulação com outras políticas sociais, com um envolvimento ainda maior de entidades privadas e dos setores cooperativo e social, além de indicar que "as políticas integradas e transversais de intervenção social junto às populações realojadas visarão à prevenção de guetos" (XVII GOVERNO CONSTITUCIONAL, 2007, p.101). O que tem sido feito nesse aspecto é o programa Prohabita, que consiste na possibilidade dos municípios, a partir de um diagnóstico, solicitar ao governo nacional financiamento para a construção ou reabilitação de apartamentos para pessoas carentes.

A execução da construção ou da reabilitação pode ser feita pelo próprio município ou este pode repassar o recurso para uma instituição de solidariedade social e/ou cooperativas de habitação e construção fazê-lo, conforme previsto no Decreto-Lei no 135/2004, que cria o Prohabita. São recorrentes casos - como os que serão aqui analisados - em que o Estado transfere quase completamente a responsabilidade por essas intervenções nas cidades para as instituições de solidariedade social e para as cooperativas de habitação e construção. Outra ação que se diz ter interesse de executar é a "adequação das condições de habitabilidade a situações específicas”, em que a preocupação central, segundo o programa do governo, é com os idosos e os cidadãos portadores de deficiência.

No segundo eixo, existe também o Programa Especial de Realojamento (PER), o qual tem o intuito de erradicação de habitações precárias nas áreas metropolitanas de Lisboa e do Porto. Além do realojamento, esse programa prevê uma revitalização dos imóveis municipais e também a realização de ações sociais para acompanhar o processo de integração social das famílias, garantindo-lhes condições para que, no futuro, possam ter suas próprias moradias. Outro projeto que se pretende continuar é o de incentivo à construção de habitações com custos controlados, a chamada "habitação apoiada", iniciativa que vem sendo igualmente promovida através de parcerias entre os municípios e o setor cooperativo.

Por fim, o terceiro eixo, o de requalificação do tecido urbano, relaciona-se à percepção do Estado de que a política de habitação deve estar articulada com as políticas de:

requalificação e revitalização das cidades e com o desenvolvimento pelas autarquias locais, em parceria com a administração central, de programas de intervenção nas áreas mais críticas das grandes cidades, que possam reabilitar o parque degradado e requalificar o ambiente urbano. (XVII GOVERNO CONSTITUCIONAL, 2007, p.102)

Nesse sentido, propõem-se algumas ações a serem empreendidas, como o apoio à reabilitação de edifícios, a oferta de bonificações para municípios que utilizem os edifícios desocupados a serem reabilitados nas suas ações de realojamento e, até mesmo, a penalização de proprietários de imóveis devolutos. Uma iniciativa que se enquadra nos objetivos de revitalização das cidades é o Programa Polis, uma parceria entre os governos nacional e municipais para intervenção nos espaços públicos, revitalizando-os, estejam localizados nos centros urbanos, ou em bairros sociais já arrendados. 
No entanto, segundo um documento do governo (Resolução do Conselho de Ministros $\mathrm{n}^{\mathrm{o}}$ 143/2005) relacionado aos bairros críticos, o programa se mostrou insuficiente no que tange à intervenção nos bairros sociais, dedicando-se, em sua maior parte, a reformas nos centros urbanos. Destarte, os governos municipais, diante do desinteresse pela revitalização dos bairros sociais, passaram a leiloar esses patrimônios para instituições de solidariedade social ou cooperativas, as quais assumiram, portanto, a responsabilidade pela atuação nesses locais. Assim como exposto anteriormente, o governo mais uma vez transferiu integralmente uma responsabilidade sua para essas instituições, deixando totalmente a cargo destas o desenvolvimento de políticas que, teoricamente, pertencem ao seu campo de atuação, já que dizem respeito a direitos dos cidadãos residentes em Portugal.

Ao analisarmos as propostas do governo sistematizadas nesses três eixos de intervenção, bem como os programas correspondentes a cada um deles, percebe-se que o esforço pela solução das carências habitacionais não é uma preocupação central do governo português, que não se vê como o grande responsável pelas ações nesse setor. Isso pode ser considerado reflexo de uma política de perspectiva neoliberal, em que a habitação não é entendida como um direito a ser garantido pelo Estado, mas algo a ser obtido pelo esforço pessoal. Nesse contexto, o Estado, então, atua apenas de forma parcial, no sentido de oferecer apoio para que a população possa ela própria adquirir tal bem. Esse apoio está relacionado a uma tentativa de se formular políticas integradas em que a questão da habitação esteja ajustada às políticas de desenvolvimento econômico, ou seja, ligadas à criação de emprego e renda. No entanto, a partir do momento em que essas outras políticas são ineficazes e resultam em quadros de desemprego, como pode ser observado nos dias atuais no país (e em outras situações de crise), a população carente encontra graves obstáculos à aquisição de moradia.

Nesse contexto, argumenta-se que o setor cooperativo passa a se responsabilizar - como que por falta de alternativas - por um compromisso firmado constitucionalmente entre o Estado português e seus cidadãos de garantir o direito de moradia digna, pois, na prática, as cooperativas não atuam como parceiras, mas como as grandes responsáveis pela questão da habitação. Essa responsabilidade se dá tanto pela via da construção de habitações a custos controlados, destinadas em sua maior parte à classe média, quanto pela da requalificação dos bairros sociais. Esta última via possui sim um caráter mais social, numa atuação que ultrapassa a revitalização e busca oferecer um serviço de assistência social, mesmo pontual e insuficiente para atender às demandas.

Na próxima seção, apresentaremos as opções metodológicas do estudo para, então, na seguinte, analisarmos duas experiências de bairros sociais portugueses que demonstram as consequências desse posicionamento do governo português diante das políticas de habitação, bem como o papel do cooperativismo nesse contexto.

\section{Opções metodológicas}

Esta pesquisa consistiu num trabalho teórico-empírico que buscou analisar a política de habitação em Portugal pela investigação de dois casos: o de Sá Carneiro e o de São João da Talha, dois bairros sociais construídos para o realojamento de famílias carentes. Desse modo, além de consultar a literatura disponível sobre o tema, recorreu-se ao estudo de campo, o que possibilitou verificar, na prática, como é a realidade desses bairros e quais as consequências desse tipo de política habitacional para a população envolvida.

Como sugere Goldenberg (2000), as escolhas metodológicas devem ser provenientes dos objetivos da pesquisa, de modo que aqui é apresentado um estudo de múltiplos casos de caráter descritivo, abordando as principais características e limitações das políticas sociais de habitação portuguesas. O estudo teve uma abordagem qualitativa que visa interpretar o fenômeno, enfatizando seus significados e o que ele representa em termos de experiências para os participantes (VERGARA, 2000).

A técnica de coleta de dados incluiu uma vasta pesquisa documental, em que leis, decretos e programas de governo, além de reportagens de jornais e revistas foram analisadas. Os autores recorreram a várias fontes com a finalidade de se confrontar as informações, não se limitando às publicações formais do governo. A fim de complementar esses dados, foram realizadas entrevistas com seis pessoas envolvidas com políticas de 
habitação, como o presidente da Fenache e membros da Nova Habitação Cooperativa (NHC). Os relatos possibilitaram um maior entendimento do panorama português e trouxeram maior riqueza de detalhes sobre os casos estudados. Associado a isso, também foram feitas visitas aos bairros sociais estudados, para se conhecer a realidade investigada e reunir ainda mais informações consideradas relevantes.

Finalmente, os dados levantados nos documentos e nas entrevistas foram interpretados e analisados com base na técnica da análise de conteúdo. Feito isso, foram relacionados com os dados das observações, o que permitiu uma compreensão o mais ampla possível do fenômeno estudado (VERGARA, 2000). Uma limitação do estudo, entretanto, foi o fato deste não abordar diretamente a visão dos próprios moradores sobre o problema, embora esta tenha sido de certa forma apreendida por notícias de jornais e revistas com relatos desses moradores. Ainda assim, os dados obtidos na pesquisa possibilitaram uma visão abrangente sobre estes casos estudados em Portugal.

\section{Apresentação dos casos estudados}

\section{O bairro Sá Carneiro}

Batizado como bairro Dr. Francisco Sá Carneiro, nome do primeiro-ministro responsável pelo empreendimento, fica no município de Leiria e foi inaugurado em 1985. Trata-se de uma tentativa de sanar os problemas de reassentamento de centenas de desalojados vindos de ex-colônias portuguesas, que normalmente viviam em barracas espalhadas em Leiria. Conhecido apenas como bairro Sá Carneiro, é constituído por 26 blocos de oito apartamentos de tamanhos diferentes. Nele vivem pessoas oriundas de ex-colônias como Angola (35\% dos moradores), Guiné e Moçambique, bem como das ilhas Açores e da Madeira, além de alguns belgas e brasileiros. A maioria dos habitantes, no entanto, já é nascida no Concelho ${ }^{8}$ de Leiria (48\%), é majoritariamente jovem (46,5\% tem até 24 anos) e mantém uma forte raiz cultural africana, revelada na gastronomia, na forma de utilização do espaço físico, nas relações interpessoais e nas redes familiares (LEIRIA, 2006).

Em 2005, a NHC obteve o patrimônio habitacional do bairro Dr. Francisco Sá Carneiro por meio de concurso público para as instituições de solidariedade social, ou seja, passou a ter a propriedade do conjunto habitacional. O governo local, no caso, o Concelho de Leiria, não quis receber o patrimônio habitacional do extinto Igaphe órgão estatal responsável, entre outras coisas, pela administração das habitações. A tentativa de descentralizar a administração desses bairros para as câmaras municipais deveu-se ao fato da administração central perceber sua incapacidade para a gestão financeira e social dos apartamentos e das pessoas que os habitavam. No entanto, muitas das câmaras - como foi o caso de Leiria - também não quiseram gerenciar o patrimônio, que estava bastante degradado, com vários problemas (inclusive, sociais) a serem resolvidos, como colocou Albertina Mateus (presidente da NHC Social - setor da NHC que cuida das questões sociais referentes aos moradores do bairro) durante entrevista que nos concedeu.

O patrimônio recebido do Igaphe pela NHC em Leiria (NHC, 2008) corresponde, conforme já foi dito, a 26 blocos, de oito apartamentos cada, num total de 208. Destes, 144 apartamentos operam em regime de renda apoiada - (NHC Social), 44 foram comprados pelos moradores, 11 funcionam em regime de propriedade resolúvel e nove pertencem à Câmara Municipal de Leiria (estando também em regime de renda apoiada). Como explicado anteriormente, o regime de renda é uma apoio financeiro do município de Leiria concedido àquelas famílias que não conseguem pagar a "renda mensal" (espécie de aluguel) do apartamento com recursos próprios. Trata-se do Inquilinato Social, que é uma das formas de atuação da $\mathrm{NHC}^{9}$ : este consiste no arrendamento de habitações em caráter social, destinadas às famílias de parcos recursos econômicos e em situação de maior vulnerabilidade.

A outra iniciativa, as Intervenções Sociais no Bairro (NHC, 2008), cabe a uma dupla de técnicas de política social e a uma coordenadora, que desenvolvem atividades de gestão e acompanhamento social das famílias

\footnotetext{
${ }^{8}$ Concelho é em Portugal é o mesmo que município no Brasil.

${ }^{9}$ A NHC tem duas formas de atuação: uma delas oferece crédito, no sistema cooperativista, para a construção e aquisição de moradias e a outra, chamada de NHC social presta assistência aos sem-teto por meio do arrendamento subsidiado de habitações sociais.
} 
arrendatárias. As atividades desenvolvidas são as seguintes: atendimento individual e familiar; atendimento para efeito de pedido de habitação; disponibilização de informação e encaminhamento para instituições competentes; apoio na resolução de problemas do dia a dia; solução de conflitos entre os moradores pela promoção do diálogo e da participação; visitas domiciliárias; articulação com entidades parceiras; participação em projetos de intervenção integrada, focados nas problemáticas sentidas pelas famílias; realojamento e adequação de tipologias de famílias já realojadas; além da organização dos moradores em condomínios, tendo em vista a sua participação e o exercício dos deveres de cidadania.

É importante chamar atenção para os diversos problemas por que passam o bairro e que vêm ganhando cada vez mais repercussão na mídia e na sociedade portuguesas. Problemas esses que se esperava ver solucionados após o patrimônio ter passado para as mãos das cooperativas de habitação, o que não ocorreu. As tentativas do governo português de satisfazer as necessidades habitacionais das famílias que moravam em "barracas" espalhadas pela cidade se deram de forma não (ou mal) planejada, pontual e desconexa em relação aos demais problemas sociopolíticos e econômicos dessas famílias. Indício disso foi a forma como as pessoas reassentadas foram alocadas nos novos apartamentos na inauguração. Conforme relatou Albertina Mateus durante entrevista em que foram abordadas as condições precárias em que famílias e edificações se encontravam, não foi dada aos idosos a preferência de morarem nos andares mais baixos e perto das saídas dos prédios, enquanto familiares e conhecidos foram separados e vizinhos passaram a morar em blocos diferentes. Além disso, núcleos familiares de duas pessoas ocuparam apartamentos de três quartos, ao passo que famílias grandes foram amontoadas em apartamentos pequenos. Outro sinal da incapacidade do Estado português de suprir as carências dessas populações é o fato de que desde a inauguração do bairro até 2005, quando a NHC assumiu a sua administração, não havia sido feita qualquer benfeitoria e/ou reparo nos prédios ou nos apartamentos (NHC, 2008).

A NHC tomou medidas para melhorar as condições de habitação dos moradores, como: promover o realojamento de algumas famílias visando adequar o tamanho da família ao do apartamento e facilitar a locomoção dos idosos; ajustar constantemente os aluguéis, que variam dependendo da situação financeira e do número de integrantes da família, no chamado regime da renda apoiada (anteriormente, não havia revisão do aluguel); e reformar os apartamentos, prédios e áreas externas, o que passou a ser feito em 2005, ainda segundo Albertina Mateus. No entanto, apesar dos visíveis esforços das assistentes sociais da NHC, as ações promovidas pela cooperativa são extremamente limitadas e não resolvem por si só, sem o apoio de políticas governamentais, os graves problemas sociais pelos quais passam os moradores do bairro. Será possível perceber na descrição a seguir que os moradores do bairro São João da Talha passam por situação semelhante.

\section{O caso do bairro de São João da Talha}

São João da Talha é um bairro do Concelho de Loures, com cerca de 18.000 habitantes (dados de 2001). Há mais de 30 anos, sofre com o problema de famílias ciganas vivendo em conjuntos de "barracas", em condições de vida precárias, marcadas pela insalubridade e o espaço físico degradado. Por isso, através do PER, a Câmara decidiu realojar essas famílias, realizando o recenseamento das mesmas em 1993. Muitas das famílias ciganas recenseadas em 2003 ainda viviam num grupo de barracas ao lado da escola secundária. Além de ser uma situação degradante para essas famílias, isso representava um inconveniente para todos que usufruíam desse espaço público. Com o objetivo de realojar essas famílias ciganas, em abril de 2005, a Câmara de Loures assinou um protocolo firmando uma parceria com a NHC para a construção de um conjunto de 41 moradias na área sul (lote 8) do loteamento urbano promovido pela Nova Habitação Cooperativa.

O processo de concepção das moradias ocorreu entre 2005, com o estabelecimento da parceria entre a NHC e a Câmara, e 2008, quando as casas fora entregues às famílias. No primeiro semestre de 2006, foram realizadas as primeiras reuniões entre a NHC, a Câmara e as famílias, tendo em vista a seleção de quais destas seriam realojadas no conjunto e os eventuais desdobramentos. No ano seguinte, foram fixados prazos e clarificados alguns procedimentos através de um acordo, iniciando-se as reuniões entre os gabinetes jurídicos das duas instituições, visando acertar procedimentos e elaborar um contrato de arrendamento. Em janeiro de 2008, as casas foram entregues às famílias, sendo então calculados os aluguéis subsidiados e assinados os contratos de 
arrendamento. Em 25 de fevereiro procedeu-se à entrega formal das chaves nos Paços do Conselho e em $1^{0}$ de março iniciou-se, finalmente, o vínculo entre a NHC e as famílias beneficiadas (NHC, 2008).

As moradias construídas pela NHC são de sua propriedade. Portanto, a cooperativa exige das famílias que paguem um arrendamento mensal. Este é subsidiado pela Câmara Municipal de Loures, que cobre a diferença entre o arrendamento pago pelas famílias e o preço técnico da moradia. O conjunto habitacional é localizado numa região próxima do centro urbano de São João da Talha e de fácil acesso a pequenos serviços, possibilitando aos seus moradores viverem relativamente perto do local de trabalho, com acesso facilitado aos serviços públicos em geral. Adequado ao espaço público, o conjunto conta com estacionamento e espaços para convivência entre os moradores, o que é bastante positivo, visto que as famílias ciganas costumam ser numerosas e, por tradição, mantêm um estreito relacionamento entre si. Nota-se que os espaços internos carecem de mobília, o que se deve em grande parte às restrições financeiras sofridas pelos ciganos.

Quanto à futura utilização desse espaço, vários fatores indicam que pode ocorrer a degradação das casas, principalmente, devido à superlotação. Muitos afirmam que isso decorreria da falta de habilidade e educação dos ciganos. Entretanto, um inquérito feito pelo Secretariado Diocesano de Lisboa da Obra Nacional da Pastoral dos Ciganos (2001) mostrou que a comunidade, em geral, utiliza a casa de forma correta, com adequação dos compartimentos às respectivas funções. Argumenta-se que a degradação atribuída muitas vezes aos ciganos pode ser, em grande parte, consequência da já apontada superlotação, bem como das dificuldades de acesso a serviços e bens para a realização de reparos.

A construção apresenta a infraestrutura necessária para abrigar uma família nuclear média. No entanto, muitas casas se encontram superlotadas e abrigando mais de um núcleo familiar, o que é um problema, pois, por gosto e tradição, cada núcleo familiar cigano opta por viver próximo, mas em habitações separadas. Quando jovens se casam, a mulher passa a viver com a família do marido até o nascimento do primeiro filho, quando se mudam para uma casa própria. Contudo, muitas vezes, essas novas famílias não têm acesso à moradia, o que as leva a coabitar com a família do marido. Essa situação as desagrada bastante e, a fim de enfrentar o problema, são tomadas medidas como a construção de extensões anexas às moradias e a evasão para outros espaços. Isso causa muitos transtornos aos ciganos, dificultando a política de combate às moradias ilegais e a tentativa de manutenção do patrimônio.

No caso de São João da Talha, esse problema se apresentou antes mesmo da entrega das habitações, pois, o recenseamento das famílias a serem contempladas pelo programa de moradia foi feito quase 14 anos antes da entrega das habitações. Portanto, muitas mudanças ocorreram, como o crescimento do número de famílias e o envelhecimento dos filhos. Assim, em 2008, as 22 casas do programa já não contemplavam todas as 100 pessoas ocupantes das "barracas" demolidas. Esse fator gerou um grande descontentamento dos ciganos com o realojamento. Alguns chegaram até a dizer que não desocupariam suas "barracas" caso não lhes fosse atribuída uma casa na urbanização construída pela NHC. Tal situação, infelizmente, não é uma exceção, como explicita a pesquisa do Secretariado Diocesano de Lisboa (2001). Outros bairros sociais como Zambuzal, Quinta das Laranjeiras e Quinta da Fonte, apresentam o mesmo problema.

Além da construção e gestão do empreendimento, a NHC Social responde pela "gestão social", ou seja, pelo acompanhamento social dos moradores do conjunto habitacional, visando à inclusão social da comunidade cigana. As principais formas de intervenção, declaradas nas entrevistas, são:

- participação de assistentes sociais da NHC no processo de seleção das famílias realizado pela Câmara, com a intenção de conhecê-las;

- realização de seções preparatórias da ocupação e posse das casas, juntamente com técnicos da Câmara Municipal de Loures e a Pastoral dos Ciganos;

- prestação de ajuda direta às famílias, uma vez constatadas dificuldades destas adquirirem alguns equipamentos indispensáveis - como fogões e aquecedores - e de auxílio no pagamento das contas de água, de luz e de gás natural; 
- visitas ao bairro para auxiliar na ocupação do espaço;

- encaminhamento de soluções para problemas do agregado;

- ajuda na leitura e no encaminhamento de correspondências;

- realização de campanhas de vacinação e de promoção da higiene e da saúde;

- estabelecimento de parcerias com várias organizações públicas prestadoras de serviços à população;

- incentivo ao emprego para que, dessa forma, seja rompida a dependência dos subsídios sociais;

- escolarização de crianças e jovens com a criação de uma sala de educação pré-escolar e encaminhamento de jovens para os diversos níveis de ensino;

- alfabetização dos adultos; e

- promoção de uma cultura cívica entre os moradores, na qual estes devem assumir responsabilidades como inquilinos e cidadãos.

No entanto, as condições de moradia das famílias ciganas de Loures, incluindo São João da Talha, não são nem de longe ideais. Problemas como a falta de espaço e de novas moradias para as famílias recém-constituídas, superlotação de algumas casas, famílias dividindo uma mesma habitação e dificuldades financeiras que restringem o acesso a determinados bens e serviços são alguns exemplos. Além disso, podemos considerar que a retirada das famílias das condições precárias e insalubres das barracas em que viviam é positiva, pois, como demonstra a pesquisa do Secretariado Diocesano de Lisboa (2001), é errônea a ideia de que os ciganos gostam de viver em "barracas". Contudo, muito ainda deve ser feito no sentido de se criar uma forma de habitação mais integrada às necessidades desse grupo. Algumas atividades e projetos realizados pela NHC Social são indispensáveis para que a comunidade cigana adquira condições de vida melhores, no entanto, é a forma como estes são operacionalizados, em sua maior parte sem o apoio do governo por meio de políticas sociais complementares, é que os tornam pouco eficientes.

\section{Reflexões sobre os casos apresentados}

Ao analisarmos os dois casos apresentados, percebe-se que os problemas que acometem historicamente os moradores dos bairros são muito mais complexos do que a falta de moradia. Tais problemas dizem respeito à inserção desses indivíduos na sociedade portuguesa como cidadãos, iguais aos demais portugueses. Por isso envolvem aspectos e processos que têm a ver com saúde, emprego, transporte, vivência social, educação, habitação e liberdade política, entre outras coisas. Ou ainda, como argumenta Ckagnazaroff e Mota (2003), para que seja possível propiciar aos cidadãos qualidade de vida, os seus problemas devem ser tratados como se apresentam na realidade, não de forma fragmentada, mas em sua totalidade, ou seja, em um abordagem intersetorial. Esse entendimento interdisciplinar e complexo dos problemas dos cidadãos, contudo, parece não ter sido apreendido pelos responsáveis pelas políticas públicas de habitação em Portugal, que sempre trataram a questão da habitação de forma estanque.

Augusto (2002) também salienta essa visão monológica do problema da habitação, dizendo que as exigências sociais de um processo de realojamento ganham especial importância quando ponderado todo um conjunto de fatores que potenciam a exclusão social, concebida não no sentido tradicional da mera exclusão econômica (Ibidem, p.17). O referido autor chama atenção para o objetivo restrito dessas políticas de eliminação das "situações objectivas de pobreza habitacional, [que ampliam] significativamente as componentes subjectivas da exclusão" e que, além de não darem conta dos problemas existentes, torna-os mais graves ou criam outros que "potenciam e evidenciam a pobreza e a segregação" (Ibidem, p.17). Os resultados dessas políticas de habitação não poderiam ser outros senão aqueles vistos em manchetes de jornais alardeando a violência nos bairros sociais, como nos dois casos em questão. Nesse sentido, são recorrentes as notícias relacionadas a brigas entre grupos, ao tráfico de drogas, à depredação dos edifícios e áreas comuns dos condomínios e ao mau estado de conservação dos apartamentos, entre outras coisas. Associada a essas notícias está uma visão estigmatizada dos que moram nesses bairros, vistos como bárbaros que não sabem viver em sociedade, parasitas aproveitadores 
do dinheiro do Estado, pessoas incapazes de agir como cidadãs e de serem integradas na vida social da cidade e do país.

Entende-se que tanto os empreendimentos de habitação que já existiam quanto os depois construídos ou administrados pela NHC Cooperativa, apesar de intentarem a melhoria da qualidade de vida da população realojada, assim como sua inserção na sociedade, foram problemáticos, pois: (a) a relação entre Estado/direção da cooperativa e moradores é altamente verticalizada; (b) não há incentivos à participação dos moradores nas tomadas de decisões sobre o empreendimento; (c) o problema habitacional, assim como outros, é tratado de forma estanque; (d) as poucas iniciativas de cunho social têm caráter assistencialista; e, finalmente, (e) a busca de saídas para os problemas se dá de forma individualizada.

Desses pontos decorrem problemas como: (a') falta de autonomia dos moradores e reafirmação da perspectiva que atribui ao Estado o papel de provedor; (b') sentimento de incapacidade cidadã, que reforça a visão de necessidade do Estado tutelar as famílias, assim como falta de sentimento de pertencimento ao lugar; (c') impossibilidade de melhora por apenas uma via ou por vias desconexas da realidade do indivíduo, o que acarreta estagnação ou agravamento dos outros problemas vividos pelas famílias; (d') ênfase, mais uma vez, na visão do Estado provedor e da incapacidade dos indivíduos dele prescindirem; e (e') incapacidade da resolução do problema que se apresenta de forma coletiva, mas que depende dos indivíduos, demandando, assim, iniciativas que primem pela emancipação tanto individual quanto coletiva.

Além das observações feitas, é importante ressaltar que atualmente esses empreendimentos são pautados pelo discurso politicamente correto do incentivo à participação dos moradores e de sua organização para o exercício dos deveres de cidadania. Essa oportunidade, contudo, não é efetivamente garantida. Isso reforça os resultados negativos salientados anteriormente, sobretudo, no que diz respeito à incapacidade de melhora dos problemas internos e ao estigma criado tanto a respeito das famílias que moram no bairro Sá Carneiro quanto das que vivem em São João da Talha. Nesta direção, Augusto (2002) coloca:

a somar ao forte sentimento de segregação (e provando que a mera integração urbanística não é suficiente), internamente o bairro reproduz sentimentos de exclusão e bloqueios à formação de um espaço relacional, visíveis, quer na construção negativa das identidades, quer na obstaculação às sociabilidades. A resposta a uma estratégia funcionalista e individualista de realojamento familiar acaba por ser a própria dissolução da comunidade (p.17-18).

Assim, a criação dos bairros sociais tem demonstrado ser uma política de exclusão e não o contrário. Aliado às condições precárias da própria habitação, não são desenvolvidas políticas efetivas de assistência social. O setor cooperativo tem buscado atender a essa demanda, como nos casos discutidos, em que se pôde observar a importante atuação da NHC Social. No entanto, diante das dimensões do problema, que entre outras questões envolve as de natureza diversa, comuns aos dois bairros (socioeconômicas, culturais, familiares, individuais e institucionais), questiona-se qual deve ser o papel do governo. Argumenta-se, portanto, se tais problemas sociais, pela proporção que alcançaram, não seriam em grande parte consequência do posicionamento do Estado português pela "terceirização" dessas políticas.

No programa do governo atual, explicita-se que a política de habitação tem, entre seus objetivos, evitar a formação de guetos. Essa é a justificativa do governo, por exemplo, para a criação de outro bairro não analisado neste estudo: o de Quinta da Fonte. Neste, em função da Exposição Mundial de 1998, ocorrida em Lisboa, o governo realojou, às pressas, famílias ciganas e africanas em um mesmo bairro social, atualmente, o mais problemático do Concelho de Loures, em termos de violência e conflitos étnicos. Esse é mais um exemplo de atuação do governo português. Dessa forma, questiona-se: não seria a formação dos bairros sociais nada mais do que a criação de guetos?

No caso de São João da Talha, ao construir um bairro exclusivamente para a população cigana e que ainda sim não é adequado, levando-se em conta a questão cultural, o governo não estaria apenas separando os ciganos do restante da população portuguesa? Além disso, no caso de Quinta da Fonte, reunir ciganos e africanos da forma como foi feito (às pressas, sem planejamento e preparação) não gerou ainda maiores problemas sociais? Cabe 
ainda um último questionamento: Tais ações não se aproximam mais de políticas de "limpeza urbana", em que os indesejáveis são retirados dos centros urbanos e dos olhos do restante da sociedade? São questões delicadas que requerem reflexão.

\section{Considerações finais}

Com este estudo, tentamos demonstrar que a pobreza e as situações de exclusão devem ser analisadas como problemas complexos, multideterminados, que atingem grandes parcelas da população. Partindo de tal perspectiva, é imperativo ressaltar o papel do Estado como articulador das ações para enfrentamento dessa situação, a qual demanda esforços multidisciplinares, perspectivas multidimensionais e que deve ser enfrentada coletivamente. Ações com esse grau de complexidade requerem estruturas organizativas bem articuladas e pessoas capacitadas, além de poder econômico e regulatório para implementar políticas intersetoriais que tenham algum efeito. A participação também é fator crucial nessa proposta, mas os demais atores da sociedade civil devem atuar como parceiros do Estado e não como os únicos responsáveis pelo provimento dos direitos básicos do cidadão.

$\mathrm{Na}$ análise desses dois casos de portugueses, cujas ações se viabilizaram por meio de uma cooperativa de habitação, percebeu-se que o Estado, a partir do discurso da participação da sociedade civil (salvaguardado pela Constituição de 1976, chamada de Constituição socialista) e da descentralização da administração estatal (assentada na ideia de modernização da administração estatal) busca transferir a responsabilidade da promoção de políticas sociais para os agentes da sociedade civil. Tal postura é coerente com a perspectiva neoliberal de focalização e fragmentação das políticas sociais. Nesse contexto, muito mais do que o estabelecimento de relações de cooperação entre os domínios público e privado, a realidade encontrada reflete um desinteresse pela questão por parte do poder público, que passa então a responsabilidade para a iniciativa privada, sem sequer colocar-se na posição de cooperador e avaliador.

É fundamental destacar que as cooperativas tem realizado um importante trabalho, mesmo que de alcance limitado, uma vez que elas têm se dedicado à revitalização de bairros degradados, tarefa que o governo português local não tem demonstrado interesse em realizar. Assim, sem qualquer apoio estatal, as cooperativas têm tentado desenvolver trabalhos de assistência social, buscando, justamente, tratar os problemas a partir de uma perspectiva mais ampla. Entretanto, é importante destacar o quanto esse processo é dificultado se realizado isoladamente, sem apoio ou suporte do Estado, proveniente de outras políticas.

Que lições os casos estudados nos ensinam tendo em vista a realidade brasileira? A políticas habitacionais têm aqui grande relevância, pois o problema da carência de moradia atinge uma parcela significativa da população brasileira. A busca de soluções por meio de parcerias entre público e privado também tem sido cogitada, e facilitada, por exemplo, através da recente promulgação da Lei das Oscip, de 1999, que permite e regula a parceria entre pessoas jurídicas de direito privado, sem fins lucrativos (qualificando-as como Organizações da Sociedade Civil de Interesse Público). O relato dos entrevistados revelou que há uma tentativa de aproximação entre Portugal e Brasil para troca de experiências sobre a questão habitacional, especialmente no que se refere ao cooperativismo.

O fato é que o Brasil tem um histórico de importação (ou inspiração) de soluções da Europa e dos EUA para problemas internos que, em sua grande maioria, não produzem resultados satisfatórios, sendo o caso dos conjuntos habitacionais, que se assemelham ao bairros sociais estudados no caso português, um exemplo de influência malsucedida. Diante disso, torna-se fundamental uma análise criteriosa de que políticas adotar. No que se refere ao cooperativismo habitacional, é preciso considerar que a realidade brasileira é bem diferente da portuguesa: aqui há a opção do aluguel e as políticas de crédito bancário vigentes estão aos poucos ampliando a oportunidade de aquisição de imóveis pela classe média. Assim, seria necessário avaliar até que ponto o cooperativismo habitacional é vantajoso para esta camada da população e como ele se enquadraria no sistema crédito para aquisição de imóveis vigente no Brasil. 
No que se refere ao sem-teto, a política habitacional portuguesa realizada por meio de cooperativas, tem um aspecto mais focalizado, pois provê habitação de forma pontual e não definitiva, enquanto a política habitacional brasileira para estes casos, efetuada pelo governo, tem contornos mais universalistas, pois atinge um número maior de pessoas e as famílias beneficiadas se tornam proprietárias do imóveis. $\mathrm{O}$ fato é que quanto à questão da moradia popular, o caminho encontrado pelos portugueses, apesar de balizado por um discurso moderno e democrático de descentralização da administração estatal e de participação da sociedade civil, não está sendo efetivo na consecução dos objetivos propostos. Por isso, não deveria ser seguido no Brasil sem que debata amplamente suas consequências, pois os casos estudados evidenciam que a parceria público e privado na provisão de moradias populares realizada de forma a desresponsabilizar o Estado e sem o suporte de outras políticas sociais em um abordagem efetivamente intersetorial, ao invés de solucionar, contribui para aprofundar a exclusão social dos sem-teto. 


\section{Referências}

ALMEIDA, Paula. Habitação: a produção de um conceito. Sociedade e Território, Porto, n.20, p.110-116, 1994. In: AUGUSTO, Nuno Miguel. Habitação social - da intenção de inserção à ampliação da exclusão. 2002. Disponível em: <http://www.aps.pt/cms/docs_prv/docs/DPR462df3cd04e3f_1.PDF>. Acesso em: 6 abr. 2009.

AUGUSTO, Nuno Miguel. Habitação social - da intenção de inserção à ampliação da exclusão. 2002. Disponível em: <http://www.aps.pt/cms/docs_prv/docs/DPR462df3cd04e3f_1.PDF>. Acesso em: 6 abr. 2009.

BASSUL, José Roberto. Reforma urbana e Estatuto da Cidade. Eure, Santiago, Chile [online], v.28, n.84, p.133-144, set. 2002. Disponível em: <http://web.scielo.cl>. Acesso em: 26 mar. 2009.

BRONZO, Carla. Intersetorialidade como princípio e prática nas políticas públicas: reflexões a partir do tema do enfrentamento da pobreza. In: CONGRESSO DO CENTRO LATINOAMERICANO DE ADMINISTRACIÓN PARA EL DESARROLLO - CLAD, 12., 2007, Santo Doming. Anais... Venezuela: [s.n.], 2007.

CKAGNAZAROFF, Ivan Beck; MOTA, Nomaston Rodrigues. Considerações sobre a relação entre descentralização e intersetorialidade como estratégias de modernização de prefeituras municipais. E \& G. - Economia e Gestão, Belo Horizonte, v.3, n.6, p.23-41, 2003.

CORERA, Concepción Oroz. Nuevas formas de exclusión-inclusion: una propuesta de

intervención desde el trabajo social. Documento presentado en el IX Congreso de Diplomados em T.S y A.S, 2002, Madrid. In: BRONZO, Carla. Intersetorialidade como princípio e prática nas políticas públicas: reflexões a partir do tema do enfrentamento da pobreza. In: CONGRESSO DO CENTRO LATINOAMERICANO DE ADMINISTRACIÓN PARA EL DESARROLLO - CLAD, 12., 2007, Santo Domingo. Anais... Venezuela: [s.n.], 2007.

GOLDENBERG, Mirian. A arte de pesquisar: como fazer pesquisa qualitativa em ciências sociais. 4.ed. Rio de Janeiro: Record, 2000.

GUERRA, Isabel. As pessoas não são coisas que se ponham em gavetas. Sociedade e Território, Porto, n.20, 11-16p, 1994.

IHRU - INSTITUTO DE HABITAÇÃO E REABILITAÇÃO URBANA. Plano Estratégico Nacional para uma Política de Habitação - 2007/2013. 2007. Disponível em: <http://www.planoestrategicohabitacao.com/>. Acesso em: 18 abr. 2009.

. Contributo para o Plano Estratégico de Habitação - 2008-2013. Relatório I - Diagnóstico de Dinâmicas e
$\begin{array}{lll}\text { Carências } & \text { Habitacionais. } & \text { Disponível }\end{array}$ <http://www.portaldahabitacao.pt/opencms/export/sites/ihru/pt/portal/docs/Sumario_Executivo.pdf>. Acesso em: 15 out. 2010.

Disponível em: <http://www.portaldahabitacao.pt/pt/ihru/>. Acesso em: 18 abr. 2009.

LEIRIA (município, Portugal). Projecto Viver Melhor/Bairro Dr. Sá Carneiro. Leiria, 27 jan. 2006. Disponível em:

<http://www.cm-leiria.pt/pagegen.asp?SYS_PAGE_ID=807701\&id=84>. Acesso em: 13 dez. 2008.

NHC. Organização NHC Social. Disponível em: <http://www.nhc.coop/index.php?option=com_content\&task=view\&id=60\&ltemid=44>. Acesso em: 26 nov. 2008.

POLÍTICA de Habitação dos Estados Membros da UE (1996). Disponível em: <http://www.europarl.europa.eu/workingpapers/soci/w14/summary_pt.htm>. Acesso em: 5 abr. 2009.

SECRETARIADO DIOCESANO DE LISBOA DA OBRA NACIONAL DA PASTORAL DOS CIGANOS. A família cigana e a habitação. Lisboa: Edições Colibri; 2001.

SERRA, A. La gestión transversal: expectativas y resultados. Documento presentado en el IX Congreso Internacional del CLAD sobre la Reforma del Estado y de la Administración Pública, Madrid, 2004. In: BRONZO, Carla. Intersetorialidade como princípio e prática nas políticas públicas: reflexões a partir do tema do enfrentamento da pobreza. In: CONGRESSO DO CENTRO LATINOAMERICANO DE ADMINISTRACIÓN PARA EL DESARROLLO - CLAD, 12., 2007, Santo Domingo. Anais... Venezuela: [s.n.], 2007.

SILVA, Maria Alexandra Batista Ferraz da. Políticas de Habitação: seu desenvolvimento em Portugal. Coimbra: [s.n.], 2001. 118-189p.

VERGARA, Sylvia Constant. Projetos e relatórios de pesquisa em administração. 3.ed. São Paulo: Atlas, 2000. 92p.

XVII GOVERNO CONSTITUCIONAL (2007). Disponível em: <http://www.portugal.gov.pt/NR/rdonlyres/631A5B3F-54704AD7-AE0FD8324A3AF401/0/ProgramaGovernoXVII.pdf>. Acesso em: 3 abr.2009. 